\title{
Evaluation of bispectral index monitoring efficacy in endoscopic patients who underwent retrograde cholangiopancreatography and received sedoanalgesia
}

\author{
Ferda Yilmaz Inal ${ }^{1}$, Hayrettin Daskaya², Yadigar Yilmaz ${ }^{3}$, Hasan Kocoglu ${ }^{1}$ \\ ${ }^{1}$ Department of Anaesthesiology and Reanimation, Faculty of Medicine, Istanbul Medeniyet University, Istanbul, Turkey \\ 2Department of Anaesthesiology and Reanimation, Faculty of Medicine, Bezmialem Vakif University, Istanbul, Turkey \\ ${ }^{3}$ Clinic of Anaesthesiology and Reanimation, Sultan Abdülhamid Han Training and Research Hospital, Istanbul, Turkey
}

\begin{abstract}
Introduction: Bispectral index (BIS) monitoring provides an objective, non-invasive measurement of the level of consciousness in a sedated patient.

Aim: In this prospective study, we aimed to investigate the hypothesis that risk of respiratory depression could be reduced and the desired level of sedation with minimal doses of propofol could be achieved by using BIS monitoring in endoscopic retrograde cholangiopancreatography (ERCP) procedures.

Material and methods: Sixty patients in the ASA 1-2 category, who were scheduled for an ERCP with sedation, were randomly divided into two groups. The procedure was performed, and sedation was administered so that the patient's Ramsay Sedation Score (RSS) would be 4-5 in the first group (group 1) and the patient's BIS value would be 65-75 in the second group (group 2). Cardiopulmonary complications, the total duration of the procedure, and the total amount of propofol administered were recorded.

Results: The mean $\mathrm{SpO}_{2}$ measurements at the third minute, fifth minute, and $10^{\text {th }}$ minute were higher in the BIS group $(p<0.001)(p<0.05)$. The mean number of respirations during the third, fifth, $10^{\text {th }}$, and $15^{\text {th }}$ minute of sedation was significantly higher in the RSS group than in the BIS group $(p<0.05)$. There was no difference between the groups in terms of recovery time, total propofol amount, and additional doses of bolus propofol.

Conclusions: BIS monitoring during sedation with propofol for ERCP did not reduce total propofol use, but it may be an efficient guide for the timing of additional dose administration, which could reduce the risk of respiratory depression, and it could be used safely as an objective method in the follow-up of level of sedation.
\end{abstract}

Key words: sedation, bispectral index, endoscopic retrograde cholangiopancreatography.

\section{Introduction}

Endoscopic retrograde cholangiopancreatography (ERCP) is an invasive endoscopic treatment that requires deep sedation, which can sometimes be a complex, time-consuming procedure. Close monitoring of sedation and other parameters is necessary to prevent cardiovascular and respiratory problems that may occur due to the deep sedation [1-4]. Bispectral index (BIS) monitoring is an EEG-based anaesthesia-sedoanalgesia monitoring method that produces numerical scoring using a complex algorithm with electroencephalogram analysis [5]. Obtained scores vary between 0 and 100 (0, straight line EEG; 100, fully awake). BIS monitoring provides an objective, 
non-invasive measure of the level of consciousness of sedated patients and is widely used to monitor the activity of sedative anaesthetic agents and cerebral cortex [5-7]. Concerning the sedation to be administered during endoscopy, the European and American guidelines recommend close observation of the patient's physiological parameters [1-4]. In the endoscopic field, attempts were made to examine the safety and efficacy of BIS monitoring in patients who underwent endoscopy after the first application of BIS monitoring as an assistive monitoring device for sedation in 2004. BIS monitoring has also been reported to facilitate the measurement of the depth of sedation and the titration of anaesthetic agents [8].

There are studies using BIS monitoring to facilitate sedation in ERCP procedures [9-11]. The depth of anaesthesia, the amount of anaesthetic drug used, and the complications that were encountered during the ERCP studies were investigated, and different results were reported [9, 12-14].

There are several validated scoring systems available for the assessment of sedated patients and gradation of their level of sedation. One of the most commonly used measures of sedation is the Ramsay Sedation Scale (RSS). It was described by Ramsay et al. in 1974 for the purpose of monitoring sedation [15]. RSS divides a patient's level of sedation into six categories, ranging from severe agitation to deep coma (Table I).

\section{Aim}

In this prospective study, we aimed to investigate the hypothesis that risk of respiratory depression could be reduced and the desired level of sedation with minimal doses of propofol could be achieved by using BIS monitoring in ERCP procedures. For his purpose we tried to determine the effects on the respiratory functions $\left(\mathrm{SpO}_{2}\right.$, respiration rate), haemodynamic parameters, and recovery period in these patients, and to evaluate the satisfaction of the endoscopist and the patient.

\section{Material and methods}

Sixty patients who, according to the American Society of Anesthesiologists (ASA) physical classifications, were in the ASA 1-2 categories, and were scheduled for an ERCP procedure with sedation, were randomly divided into two groups after obtaining their written, informed consent and the approval of the Local Ethics Committee (Clinicaltrials.gov Identifier: NCT03114774). Patients who had a history of neurological disease (transient ischaemic attack, syncope, dementia, etc.), were allergic to the drugs that were planned to be used, were $<18$ years of age, were pregnant, or had chronic benzodiazepine/opioid drug use were excluded from the study.

All ERCP procedures were in a class between 1 and 3 according to Grading the Degree of Difficulty of ERCP Procedures [16] (Table II), performed by the same gastroenterologist, and all anaesthetic procedures were performed by the same anaesthesiologist. The patients were randomly assigned using a computer-generated randomisation table and divided into two groups. An endoscopist registered the participants at our data centre. The staff of the data centre used the randomisation function of Microsoft Excel (RAND) to randomly assign participants to the first group or second group. In the first group (RSS group), sedation was monitored by Ramsay Sedation Score (RSS), and in the second group (BIS group), sedation was monitored by BIS monitoring.

All patients were noninvasively monitored in the treatment room (electrocardiogram, blood pressure, pulse oximetry). Oxygen was administered through nasal cannula at a rate of $2 \mathrm{l} / \mathrm{min}$ from the beginning of sedation and throughout the procedure. Preoperative medication was administered to all patients using $0.03 \mathrm{mg} / \mathrm{kg}$ intravenous (IV) midazolam (Dormicum; Deva, Istanbul, Turkey).

Patients in the RSS group were administered $1 \mathrm{mg} /$ kg IV lidocaine (Aritmal 2\%; Osel, Istanbul, Turkey). Anaesthesia was maintained with $4 \mathrm{mg} / \mathrm{kg} / \mathrm{h}$ propofol infusion after a loading dose of $1 \mathrm{mg} / \mathrm{kg}$ propofol (propofol 1\%; Fresenius Kabi, Istanbul, Turkey),

Table I. Ramsay Sedation Scale

\begin{tabular}{|lr|}
\hline Level & Characteristics \\
\hline 1 & Patient awake, anxious, agitated, or restless \\
\hline 2 & Patient awake, cooperative, orientated, and tranquil \\
\hline 3 & Patient drowsy, with response to commands \\
\hline 4 & Patient asleep, brisk response to glabella tap or \\
& loud auditory stimulus \\
\hline 5 & Patient asleep, sluggish response to stimulus \\
\hline 6 & Patient has no response to firm nail-bed pressure \\
& or other noxious stimuli \\
\hline
\end{tabular}


Table II. Comparison of two groups in terms of demographic and clinical characteristics

\begin{tabular}{|c|c|c|c|}
\hline Parameter & $\begin{array}{l}\text { RSS group } \\
(n=30)\end{array}$ & $\begin{array}{l}\text { BIS group } \\
(n=30)\end{array}$ & $P$-value \\
\hline Age $^{¥}$, mean \pm SD [years] & $56.16 \pm 11.510$ & $53.30 \pm 8.921$ & 0.285 \\
\hline Male* $^{*} n(\%)$ & $16(53.3)$ & $10(33.3)$ & 0.192 \\
\hline Female $^{\star}, n(\%)$ & $14(46.7)$ & $20(66.7)$ & \\
\hline Weight ${ }^{*}$, mean \pm SD $[\mathrm{kg}]$ & $74.53 \pm 14.001$ & $75.03 \pm 14.59$ & 0.893 \\
\hline Height ${ }^{*}$, mean \pm SD $[\mathrm{cm}]$ & $168.23 \pm 10.401$ & $164.3 \pm 5.80$ & 0.076 \\
\hline ASA I $I^{*} n(\%)$ & $12(40.0)$ & $17(56.7)$ & 0.301 \\
\hline ASA $\|^{\star}, n(\%)$ & $18(60.0)$ & $13(43.3)$ & \\
\hline Comorbidity $^{*}, n(\%)$ : & & & 0.169 \\
\hline None & $12(40.0)$ & $17(56.7)$ & \\
\hline$\overline{\mathrm{HT}}$ & $7(23.3)$ & $5(16.7)$ & \\
\hline$\overline{D M}$ & $0(0.0)$ & $2(6.7)$ & \\
\hline COPD & $0(0.0)$ & $2(6.7)$ & \\
\hline $\mathrm{CHD}$ & $2(6.7)$ & $0(0.0)$ & \\
\hline$\overline{R A}$ & $1(3.3)$ & $0(0.0)$ & \\
\hline Thyroid disease & $1(3.3)$ & $2(6.7)$ & \\
\hline $\mathrm{HT}$ and COPD & $5(16.7)$ & $1(3.3)$ & \\
\hline $\mathrm{HT}$ and $\mathrm{CHD}$ & $1(3.3)$ & $0(0.0)$ & \\
\hline $\mathrm{DM}$ and thyroid disease & $1(3.3)$ & $1(3.3)$ & \\
\hline Indications ${ }^{*}, n(\%)$ : & & & 0.154 \\
\hline Choledocholithiasis & $10(33)$ & $14(36)$ & \\
\hline Biliary leaks & $7(23)$ & $2(6)$ & \\
\hline Biliary stenosis & $6(20)$ & $6(20)$ & \\
\hline Stent exchange & $2(6)$ & $3(10)$ & \\
\hline Stent extraction & $2(6)$ & $2(6)$ & \\
\hline Others & $3(10)$ & $3(10)$ & \\
\hline
\end{tabular}

EMann-Whitney U test; ${ }^{*}$ independent samples $t$-test; ${ }^{*}$ Fisher-Freeman-Halton test. HT - hypertension, DM - diabetes mellitus, COPD - chronic obstructive pulmonary disease, CHD - coronary heart disease, $R A$ - rheumatoid arthritis.

$1 \mu \mathrm{g} / \mathrm{kg}$ fentanyl (fentanyl, Johnson and Johnson, Istanbul, Turkey) [17-19]. In the RSS group, the propofol infusion rate was reduced or an additional bolus of $0.1 \mathrm{mg} / \mathrm{kg}$ IV propofol was applied, in order to achieve a sedation depth of 4-5 on the RSS scale (Table I). The number of additional propofol boluses was recorded. In the BIS group, a BIS electrode was fixed on the frontotemporal region and BIS values were monitored (Aspect Medical Systems, Covidien, MA, USA). In the same way as in the RSS group, 1 $\mathrm{mg} / \mathrm{kg}$ IV lidocaine was administered. After administration of loading doses of $1 \mathrm{mg} / \mathrm{kg}$ IV propofol and $1 \mu \mathrm{g} / \mathrm{kg}$ IV fentanyl, anaesthesia was maintained with a propofol infusion of $4 \mathrm{mg} / \mathrm{kg} / \mathrm{h}$. The sedation depth was achieved by decreasing the propofol infusion rate to reach a BIS value of $65-75$ or by an additional bolus of $0.1 \mathrm{mg} / \mathrm{kg}$ IV propofol.

Heart rate (HR), systolic arterial pressure (SAP), diastolic arterial pressure (DAP), mean arterial pressure (MAP), peripheral arterial oxygen saturation 
$\left(\mathrm{SpO}_{2}\right)$, and respiratory rate $(\mathrm{RR})$ were monitored and recorded every $5 \mathrm{~min}$.

In the case of hypoxia $\left(\mathrm{SpO}_{2}<90 \%\right)$, nasal oxygen was increased $>2 \mathrm{l} / \mathrm{min}$ while the jaw and mask ventilation were lifted. In the case of hypotension (systolic arterial pressure $<80 \mathrm{~mm} \mathrm{Hg}$ ), necessary interventions (fluid replacement, ephedrine application) were performed. In the case of bradycardia ( $<50 / \mathrm{min}$ ), necessary interventions (drug titration, IV atropine) were planned. Cardiopulmonary events and interventions performed were recorded.

The duration of total anaesthesia for the procedure (for the RSS group, calculated from initiation of the IV anaesthetic agent to reaching an RSS value of 2; for the BIS group, calculated from the initiation of the IV anaesthetic agents to reaching a BIS value of 90) and the total amount of propofol administered were recorded.

After completion of the procedure, the patients were taken to the recovery unit if their haemodynamic data were stable. Recovery was monitored by the Aldrete recovery score (ARS) (0-10) [20]. Patients with an ARS of 9 were discharged from the recovery unit. Monitoring of nausea and vomiting in the recovery unit was carried out by the Numerical Rank Score (NRS).

The endoscopist was asked to score their satisfaction between 0 and 4 (4: very good, 3: good, 2: bad, 1: very bad). Patients were asked to score between 0 and 4 (4: no discomfort, 3: slightly uncomfortable, 2: extremely uncomfortable, 1: unacceptable) after the $A R S \geq 9$, for evaluation of their satisfaction with the sedation performed during the procedure.

\section{Statistical analysis}

Descriptive statistics for numerical variables were evaluated as the mean and standard deviation, and descriptive values for categorical variables are presented as number and percentage. Adaptation of numerical measurements to a normal distribution was analysed by the Kolmogorov-Smirnov test. The differences between the two groups in terms of socio-demographic and some clinical characteristics were examined using either the independent samples $t$-test, Mann-Whitney $U$ test, ANCOVA model, or Fisher-Freeman-Halton test, depending on the type and distribution of the characteristics. In the comparison of the two groups in terms of HR, SAP, DAP, $\mathrm{MAP}, \mathrm{SpO}_{2}$, and RR measured at different periods, the independent samples $t$-test or Mann-Whitney $U$ test was used, depending on the data type. A $p$-value $<0.05$ was considered statistically significant. The Statistical Package for the Social Sciences version 22.0 (IBM Corporation, Armonk, NY, USA) software was used for the statistical analysis.

\section{Results}

\section{Demographic and clinical characteristics of patients}

A total of 30 patients were included in the BIS group and 30 in the RSS group. No patient was excluded after randomisation. Baseline demographics and clinical characteristics of patients were similarly distributed between the groups (Table II).

\section{Pulmonary events}

$\mathrm{SpO}_{2}\left(3^{\text {rd }} \mathrm{min}\right), \mathrm{SpO}_{2}\left(5^{\text {th }} \mathrm{min}\right)$, and $\mathrm{SpO}_{2}\left(10^{\text {th }} \mathrm{min}\right)$ measurements were found to be significantly higher in the BIS group $(p<0.001)(p<0.05)$ (Figure 1).

In the BIS group, the number of patients who had no drop in $\mathrm{SpO}_{2}(<90 \%)$ was 19 (63.3\%), which was significantly higher than the number in the RSS group, whereas seven patients showed a drop three times $(23.3 \%)$ in the RSS group, which was significantly fewer than the number of patients in the BIS group (0 patients $0 \%)(p<0.05)$. Increasing nasal $\mathrm{O}_{2}$ $>2 \mathrm{l} / \mathrm{min}$ as an intervention for hypoxia was more common in the RSS group than the BIS group (8 (26.6\%) patients) $(p<0.001)$ (Table III). Lifting of the jaw was needed in one patient in the RSS group, while it was not needed in any patient in the BIS group.

Mean respiratory rates at the third, fifth, $10^{\text {th }}$, and $15^{\text {th }}$ minutes of sedation were significantly higher in the RSS group than in the BIS group $(p<0.05)$ (Figure 2).

\section{Propofol dose}

The mean (SD) total propofol dose administered was 216.0 (124.67) $\mathrm{mg}$ in the BIS group, and 207.0 (60.41) $\mathrm{mg}$ in the RSS group. No significant differences were observed between the two study groups in terms of the total amount of propofol and additional doses of propofol bolus $(p>0.05)$ (Table IV).

\section{Quality of sedation}

The endoscopist rated patient sedation as very good/good for all the patients in both groups. All pa- 


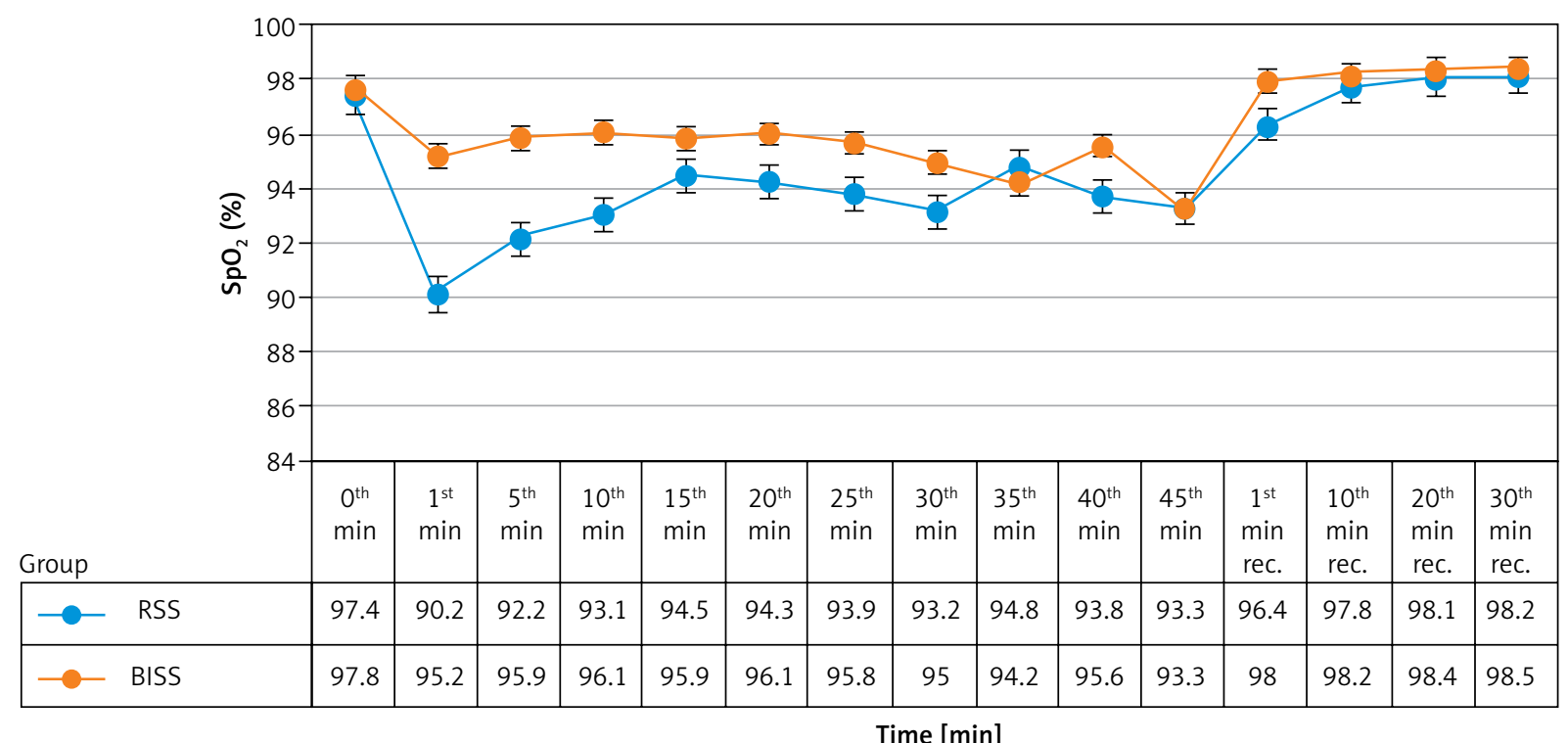

Figure 1. Comparison of $\mathrm{SpO}_{2}$ values

Table III. Number of drops in $\mathrm{SpO}_{2}(<90 \%)$ and interventions related to it*

\begin{tabular}{|lccc|}
\hline Parametr & $\begin{array}{c}\text { RSS group } \\
(n=30)\end{array}$ & $\begin{array}{c}\text { BIS group } \\
(n=30)\end{array}$ & $P$-value \\
\hline $\begin{array}{l}\text { Number of } \\
\text { drops in } \mathrm{SpO}_{2} \\
n(\%):\end{array}$ & $10(33.3)$ & $19(63.3)$ & 0.010 \\
\hline $\begin{array}{l}\text { 0 time } \\
1 \text { time }\end{array}$ & $9(30.0)$ & $6(20.0)$ & 0.402 \\
\hline 2 times & $4(13.3)$ & $5(16.7)$ & 0.816 \\
\hline 3 times & $7(23.3)$ & $0(0)$ & 0,010 \\
\hline $\begin{array}{l}\text { Increasing } \\
\text { nasal } \mathrm{O}_{2} \\
>2 \text { l/min, } n \text { (\%) }\end{array}$ & $18(60.0)$ & $8(26.6)$ & 0.001 \\
\hline $\begin{array}{l}\text { Jaw lifting, } \\
n \text { (\%) }\end{array}$ & $1(3.3)$ & $0(0.0)$ & 0.321 \\
${ }^{*}$ Fisher-Freeman-Halton test was used. & \\
\hline
\end{tabular}

${ }^{*}$ Fisher-Freeman-Halton test was used.

tients in both groups rated their level of satisfaction as high (no discomfort) (Table IV).

\section{Recovery}

Recovery times of patients to have an ARS of 9 were similar in the two groups (Table IV).

\section{Cardiovascular events}

None of the patients had bradycardia. Hypotension was observed in only one patient in the RSS group $(3.3 \%)$ and was treated with fluid replacement.

No significant difference was found between the two groups in terms of HR, SAP, DAP, and MAP during the sedation and recovery periods.

\section{Discussion}

ERCP procedures require deep sedation and have a higher complication rate than do other endoscopic procedures [21-23]. Studies regarding BIS monitoring during sedation in order to monitor sedation levels, reduce the use of anaesthetic agents, and prevent complications during ERCP procedures report varying results [9, 12-14]. Therefore, ERCP cases were chosen in this study. We investigated the hypothesis that the risk of respiratory depression could be reduced by decreasing the propofol dose while providing the desired sedation level with BIS monitoring. In previous studies, it was reported that the mean amount of propofol used for sedation in patients undergoing an ERCP procedure was lower and that a more effective titration was achieved in the BIS group $[8,11,14]$. In some studies, only propofol was used for sedation in these patients, and different pain levels were not homogenised because no analgesic agent was added [11, 14]. In another study, when midazolam was added to propofol and sedation was achieved, the tendency to use less propofol was noted in the BIS group, although there was no statistically significant difference. In a meta-analy- 


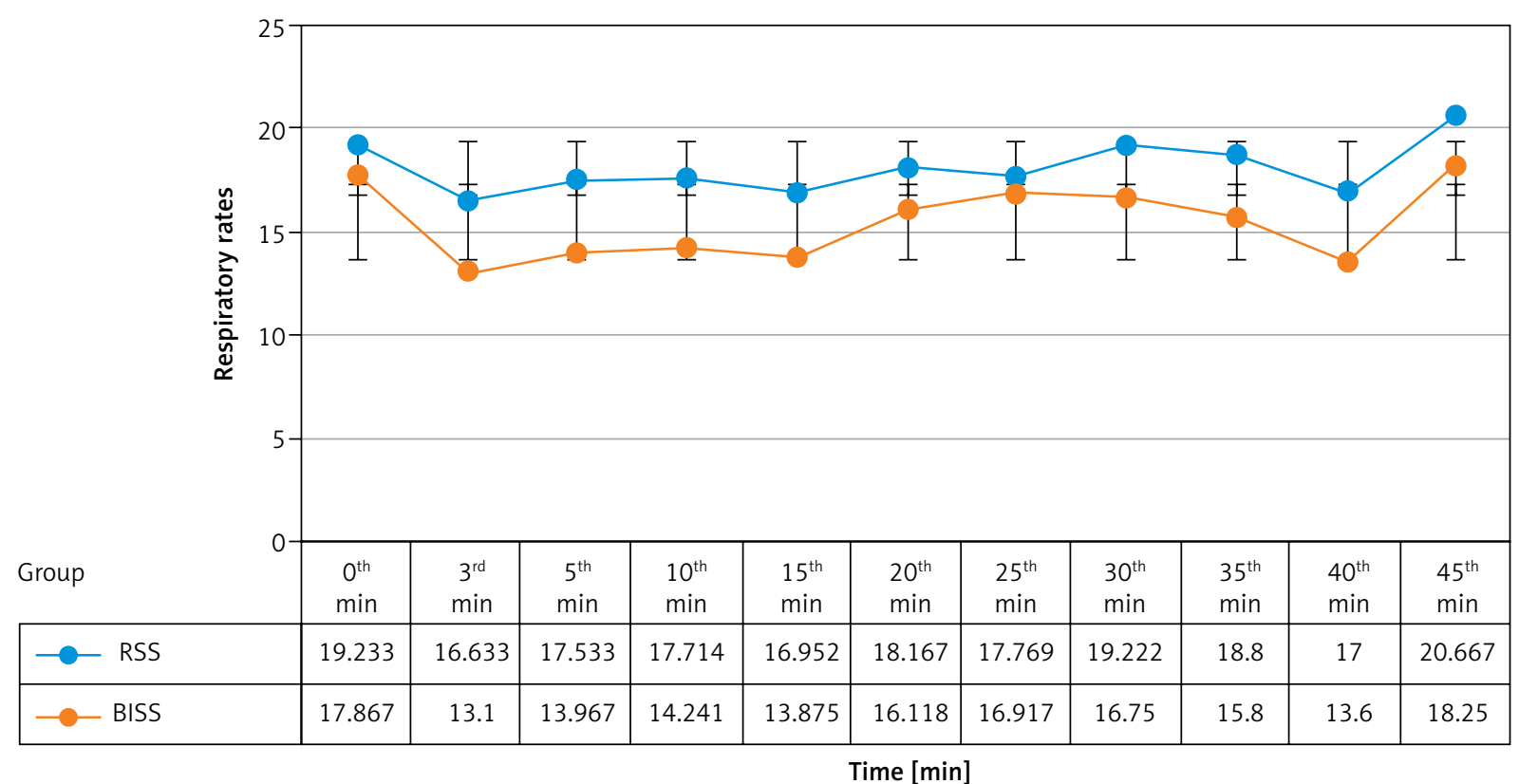

Figure 2. Comparison of respiratory rates

Table IV. Duration of anaesthesia, recovery time, NRS values, total amount of propofol, additional doses of propofol bolus, and endoscopist and patient satisfaction

\begin{tabular}{|c|c|c|c|}
\hline Paramater & $\begin{array}{l}\text { RSS group } \\
(n=30)\end{array}$ & $\begin{array}{l}\text { BIS group } \\
(n=30)\end{array}$ & $P$-value \\
\hline Duration of anaesthesia ${ }^{*}$, mean $\pm S D$ [min] & $27.23 \pm 14.488$ & $24.33 \pm 11.80$ & 0.399 \\
\hline Recovery time ${ }^{\ddagger}$, mean $\pm S D[$ min $]$ & $10.83 \pm 6.308$ & $9.16 \pm 5.583$ & 0.283 \\
\hline Total amount of propofol ${ }^{*}$, mean \pm SD [mg] & $216.0 \pm 124.67$ & $207.0 \pm 60.41$ & 0.724 \\
\hline Additional doses of propofol ${ }^{*}$, mean \pm SD & $5.10 \pm 7.336$ & $4.03 \pm 4.055$ & 0.489 \\
\hline Endoscopist satisfaction ${ }^{£}$, mean \pm SD & $3.50 \pm 0.682$ & $3.76 \pm 0.430$ & 0.092 \\
\hline Patient satisfaction ${ }^{£}$, mean \pm SD & $3.93 \pm 0.253$ & $3.90 \pm 0.305$ & 0.643 \\
\hline
\end{tabular}

EMann-Whitney $U$ test, ${ }^{*}$ independent samples t-test.

sis, it was found that total propofol consumption under BIS monitoring was significantly lower than that in patients receiving no BIS monitoring [24]. However, this meta-analysis investigating a total of 11 studies consisted of multiple heterogeneous groups, and all gastrointestinal endoscopic procedures were included. The absence of a difference between the groups in terms of the total propofol amount used in our study may be related to the homogenisation of the patient groups by conducting the study only in patients undergoing an ERCP, and the exclusion of the pain factor by the addition of an opioid to the propofol.

Cardiopulmonary events are the most common cause of mortality in patients undergoing an ERCP.
Therefore, prevention of these complications is crucial. It was thought that BIS monitorisation would prevent these complications by regulating sedation levels while avoiding respiratory depression, and this issue has been investigated in multiple studies. Paspatis et al. reported in their study that they did not find any difference between the groups with and without BIS monitoring in terms of $\mathrm{SpO}_{2}$ values [14]. However, the oxygen flow in this study was set at $5 \mathrm{l} / \mathrm{min}$. In our study, the oxygen flow was set to $2 \mathrm{l} / \mathrm{min}$, and thus the data were strengthened by making patients more sensitive to desaturation.

The effect of propofol starts fast and terminates quickly, due to the high lipid solubility, redistribution, and elimination. After a single dose of injection (2- 
$3 \mathrm{mg} / \mathrm{kg}, \mathrm{IV})$, the hypnotic effect starts after 30-40 s, and the duration of effect is about 4-8 $\min [25,26]$. It is rapidly and widely distributed to highly perfused tissues such as the brain after intravenous administration [27]. The onset of anaesthesia is provided within the arm-brain circulation [28]. Therefore, to evaluate the effect of bolus propofol dose applied in induction in our study, $\mathrm{SpO}_{2}$ values were recorded at third, fifth, and $10^{\text {th }} \mathrm{min}$.

According to our findings, BIS monitoring did not affect the amount of propofol consumed, but it was effective in reducing the risk of respiratory depression. In our study, we can state that the number of drops in $\mathrm{SpO}_{2}$ values was high in the RSS group and was seen at the first, fifth, and $10^{\text {th }}$ minutes of the procedure. Although it has not been recorded, additional doses of propofol in the RSS group at the very beginning of the procedure, which we found in our clinical observation, also contribute to this finding. In our study, clinically, when the RSS scale is 4-5 and the procedure started with the initial entrance of the endoscope, it was observed that some patients could move, RSS values were decreased, the additional doses of bolus propofol were needed, and after additional doses respiratory depression developed leading to drops in $\mathrm{SpO}_{2}$ values. The fact that respiratory rates were significantly higher in the RSS group at the first, fifth, $10^{\text {th }}$ and $15^{\text {th }}$ min was determined to be a response to compensation for the simultaneous drops in $\mathrm{SpO}_{2}$. In $\mathrm{BIS}$ monitoring, we observed that there was no need to add additional dose propofol at the first entry because the endoscope entry was made when the patient's BIS value was 75 , which means that the decrease in $\mathrm{SpO}_{2}$ value was lower.

Although the total amount of propofol used is the same, BIS monitoring may be a better guide for the additional dose of propofol based on objective data than the clinical observation-based RSS. Thus, we can state that it can help reduce respiratory depression.

It has been reported that BIS monitoring during an ERCP can affect the recovery time by preventing deep sedation. Paspatis et al. reported that the recovery time was shorter in the BIS group, which could be explained by the decreased amount of propofol used in that group [14]. Von Delius et al. also reported that in the BIS group less propofol was consumed and a shorter recovery time was detected [12]. In our study, the similarity of duration of recovery in both groups can be explained by the different propofol doses and similar procedure times.
In this study, similarly high values were achieved in both groups in terms of patient and endoscopist satisfaction. Due to the decrease in $\mathrm{SpO}_{2}$ values in the first $15 \mathrm{~min}$ of the procedure seen in the RSS group, the endoscopist satisfaction rate could be expected to be low. However, management of anaesthesia without any impact on the procedure may be interpreted as not affecting endoscopist satisfaction. Contrary to our findings, Imagawa et al. reported that patient and endoscopist satisfaction scores were higher when BIS was used to monitor propofol sedation for endoscopic submucosal dissection [29]. This may be related to whether or not endoscopists are blind to the presence of BIS monitoring during the procedure.

Our study has several limitations. The endoscopist and the anaesthesiologist were not blind and we did not record the additional doses of propofol given in the event of sedation insufficiency (if we had recorded them, we could have documented that they were higher in the first $15 \mathrm{~min}$ of sedation and therefore drops in $\mathrm{SpO}_{2}$ were more common in the RSS group). Additionally, although the sample size was sufficient for the study, it could have been larger (the larger number of patients could have made the results more reliable).

\section{Conclusions}

As a result, it was concluded that BIS monitoring during sedation with propofol for ERCP did not reduce total propofol use but may be an efficient guide for timing of additional dose administration, which could reduce the risk of respiratory depression, and it could be used safely as an objective method in the follow-up of the level of sedation in these patients.

\section{Conflict of interest}

The authors declare no conflict of interest.

\section{References}

1. Dumonceau JM, Riphaus A, Aparicio JR, et al. European Society of Gastrointestinal Endoscopy, European Society of Gastroenterology and Endoscopy Nurses and Associates, and the European Society of Anaesthesiology Guideline: Non-anesthesiologist administration of propofol for Gl endoscopy. Endoscopy 2010; 42: 960-74.

2. Riphaus A, Wehrmann T, Weber B, et al. Sektion Enoskopie im Auftrag der Deutschen Gesellschaft für Verdauungs- und Stoffwechselerkrankungen e.V. (DGVS); Bundesverband Niedergelassener Gastroenterologen Deuschlands e. V. (Bng); Chiru- 
rgische Arbeitsgemeinschaft für Endoskopie und Sonographie der Deutschen Gesellschaft für Allgemein- und Viszeralchirurgie (DGAV); Deutsche Morbus Crohn/Colitis ulcerosa Vereinigung e. V. (DCCV); Deutsche Gesellschaft für Endoskopie Assistenzpersonal (DEGEA); Deutsche Gesellschaft für Anästhesie und Intensivmedizin (DGAI); Gesellschaft für Recht und Politik im Gesundheitswesen (GPRG). [S3-guidelines - Sedation in gastrointestinal endoscopy]. Z Gastroenterol 2008; 46: 1298-330.

3. Cohen LB, Delegge MH, Aisenberg J, et al. AGA Institute review of endoscopic sedation. Gastroenterology 2007; 133: 675-701.

4. Standards of Practice Committee of the American Society for Gastrointestinal Endoscopy. Lichtenstein DR, Jagannath S, Baron TH, et al. Sedation and anesthesia in GI endoscopy. Gastrointest Endosc 2008; 68: 815-26.

5. Soehle M, Ellerkmann RK, Grube M, et al. Comparison between bispectral index and patient state index as measures of the electroencephalographic effects of sevoflurane. Anesthesiology 2008; 109: 799-805.

6. Glass PS, Bloom M, Kearse L, et al. Bispectral analysis measures sedation and memory effects of propofol, midazolam, isoflurane, and alfentanil in healthy volunteers. Anesthesiology 1997; 86: 836-47.

7. Yang KS, Habib AS, Lu M, et al. A prospective evaluation of the incidence of adverse events in nurse-administered moderate sedation guided by sedation scores or Bispectral Index. Anesth Analg 2014; 119: 43-8.

8. Chen SC, Rex DK. An initial investigation of bispectral monitoring as an adjunct to nurse-administered propofol sedation for colonoscopy. Am J Gastroenterol 2004; 99: 1081-6.

9. Al-Sammak Z, Al-Falaki MM, Gamal HM. Predictor of sedation during endoscopic retrograde cholangiopancreatography - bispectral index vs clinical assessment. Middle East J Anesthesiol 2005; 18: 141-8.

10. Krugliak P, Ziff B, Rusabrov Y, et al. Propofol versus midazolam for conscious sedation guided by processed EEG during endoscopic retrograde cholangiopancreatography: a prospective, randomized, doubleblind study. Endoscopy 2000; 32: 677-82.

11. Wehrmann T, Grotkamp J, Stergiou N, et al. Electroencephalogram monitoring facilitates sedation with propofol for routine ERCP: a randomized, controlled trial. Gastrointest Endosc 2002; 56: 817-24.

12. von Delius S, Salletmaier $\mathrm{H}$, Meining A, et al. Bispectral index monitoring of midazolam and propofol sedation during endoscopic retrograde cholangiopancreatography: a randomized clinical trial (the EndoBIS study). Endoscopy 2012; 44: 258-64.

13. Jang SY, Park HG, Jung MK, et al. Bispectral index monitoring as an adjunct to nurse-administered combined sedation during endoscopic retrograde cholangiopancreatography. World I Gastroenterol 2012; 18: 6284-9.

14. Paspatis GA, Chainaki I, Manolaraki MM, et al. Efficacy of bispectral index monitoring as an adjunct to propofol deep sedation for ERCP: a randomized controlled trial. Endoscopy 2009; 41: 1046-51.

15. Ramsay MA, Savege TM, Simpson BR, Goodwin R. Controlled sedation with alphaxalone-alphadolone. Br Med J 1974; 2: 656-9.

16. Stephen M. Schutz, MD. Grading the degree of difficulty of ERCP procedures. Gastroenterol Hepatol 2011; 7: 674-6.
17. Michel Foehn ER. Adult and pediatric anesthesia/sedation for gastrointestinal procedures outside of the operating room. Curr Opin Anaesthesiol 2015; 28: 469-77.

18. Youn AM, Ko YK, Kim YH. Anesthesia and sedation outside of the operating room. Korean J Anesthesiol 2015; 68: 323-31.

19. Practice Guidelines for Moderate Procedural Sedation and Analgesia 2018: a report by the American Society of Anesthesiologists Task Force on Moderate Procedural Sedation and Analgesia, the American Association of Oral and Maxillofacial Surgeons, American College of Radiology, American Dental Association, American Society of Dentist Anesthesiologists, and Society of Interventional Radiology. Anesthesiology 2018; 128: 437-79.

20. Aldrete JA, Kroulik D. A postanesthetic recovery score. Anesth Analg 1970; 49: 924-34.

21. Qadeer MA, Vargo JJ, Patel S, et al. Bispectral index monitoring of conscious sedation with the combination of meperidine and midazolam during endoscopy. Clin Gastroenterol Hepatol 2008; 6: 102-8.

22. Woods SD, Chung SC, Leung JW, et al. Hypoxia and tachycardia during endoscopic retrograde cholangiopancreatography: detection by pulse oximetry. Gastrointest Endosc 1989; 35: 523-5.

23. Wong PY, Lane MR, Hamilton I. Arterial oxygen saturation during endoscopic retrograde cholangiopancreatography. Endoscopy 1993; 25: 309-10.

24. Park SW, Lee H, Ahn H. Bispectral Index versus standard monitoring in sedation for endoscopic procedures: a systematic review and meta-analysis. Dig Dis Sci 2016; 61: 814-24.

25. Barr J. Propofol. A new drug for sedation in intensice care unit. Int Anesthesiol Clin 1995; 33: 131-54.

26. Reves GJ, Glass PS, Lubersky DA, McEvoy MD. Intravenous nonopioid anesthetics. In: Anesthesia. $6^{\text {th }}$ edn. Miller RD (ed). Pennsylvania Churchill Livingstone, Philadelphia 2005; 317-78.

27. Cockshoot ID. Propofol pharrnacokineticks and metabolism an overview. Postgrad Med J 1985; 61: 45-50.

28. De Grood M, Mitsukuri S, Van Egmond J. Comparison of etomidate and propofol for anesthesia in microlaryngeal surgery. Anaesth 1987; 42: 366-72.

29. Imagawa A, Fujiki S, Kawahara Y, et al. Satisfaction with bispectral index monitoring of propofol-mediated sedation during endoscopic submucosal dissection: a prospective, randomized study. Endoscopy 2008; 40: 905-9.

Received: 8.01.2020, accepted: 15.02.2020. 